\title{
Incidence and origin of non-systemic microdeposits of amyloid
}

\author{
MORDECHAI RAVID, JOSEPH GAFNI, EZRA SOHAR, AND \\ HANS-PETER MISSMAHL ${ }^{1}$ \\ From the Department of Clinical Investigation, Tel-Aviv University Medical School and \\ Tel-Hashomer Hospital, Tel-Aviv, Israel
}

SYNOPSIS In a general hospital, 391 consecutive necropsies in which at least seven organs were available, were examined retrospectively by polarizing microscopy of Congo-red-stained sections for the presence of local amyloid deposits.

Non-systemic microdeposits of amyloid were encountered in 72 cases, an overall incidence of $18.4 \%$. They were usually small and frequently detectable only by virtue of polarizing microscopy. There is no indication that these microdeposits of amyloid are of pathogenetic significance. Although they sometimes occur in more than one organ, such deposits can be readily distinguished from those of systemic amyloidosis by their histological features.

The incidence of local deposits of amyloid is unknown, since necropsy material is not routinely studied appropriately. The recognition of amyloid deposits in localized form prompted surveys of favoured organs and resulted in the delineation of 'senile cardiac amyloidosis' (Hüsselmann, 1955; Buerger and Braunstein, 1960; Pomerance, 1965; Schwartz and Kurucz, 1965), 'cerebral amyloidosis of presenile and senile psychosis' (Missmahl and Hartwig, 1954; Schwartz, Kurucz, and Kurucz, 1965), amyloidosis of the islets of Langerhans in diabetes (Gellerstedt, 1938; Ehrlich and Ratner, 1961) and in functioning islet cell carcinomas (Porta, Yerry, and Scott, 1962), and in amyloidosis in solid medullary carcinoma of the thyroid (Vassar and Culling, 1961).

No systematic study has as yet been undertaken to determine the incidence of local amyloid deposits in all organs of the body. This fact and the availability of a sensitive method for detecting with assurance even minimal amyloid deposits (Heller, Missmahl, Sohar, and Gafni, 1964; Blum and Sohar, 1962) prompted this investigation.

\section{MATERIAL AND METHODS}

This study is a retrospective one. All available paraffin blocks of tissues routinely obtained at 400 consecutive necropsies performed during 1963 at the Tel-Hashomer ${ }^{1}$ Present address: Medizinische Universitaetsklinik Tuebingen, West Germany.

Received for publication 27 June 1966.
Hospital were studied. At least seven organs had been preserved in each of the cases. Kidney, liver, spleen, lung, and heart were available in $90 \%$ or more, adrenal and pancreas in over $70 \%$, and brain and thyroid in over $50 \%$ (Table I). Tissues were sectioned, stained with Congo red, and examined by ordinary and polarized light microscopy (Heller et al., 1964). Only those specimens in which the characteristic green anomalous polarization colour could be demonstrated were considered positive for amyloid. There were nine cases of generalized amyloidosis among the 400 necropsies. Since we are not concerned in this paper with generalized amyloidosis, 391 remained for the survey on local amyloid deposits.

Upon completion of the microscopical studies, clinical and pathological data were reviewed from the patients'

TABLE I

INCIDENCE OF AMYLOID DEPOSITS ACCORDING TO ORGAN

\begin{tabular}{lcc} 
Organ & Positive & $\begin{array}{c}\text { Total } \\
\text { Examined }\end{array}$ \\
\hline Adenohypophysis & $15(37 \cdot 5 \%)$ & 42 \\
Islets & $27(9 \cdot 6 \%)$ & 281 \\
Adrenal & $16(5 \cdot 5 \%)$ & 289 \\
Brain & $12(5 \cdot 3 \%)$ & 226 \\
Arteries & $2(2 \cdot 6 \%)$ & 78 \\
Heart & $9(2 \cdot 6 \%)$ & 349 \\
Lung & $6(1 \cdot 7 \%)$ & 354 \\
Pancreas & $4(1.4 \%)$ & 281 \\
Kidney & $5(1 \cdot 4 \%)$ & 367 \\
Intestine & $1(1.0 \%)$ & 103 \\
Thyroid & $1(0.5 \%)$ & 200 \\
Spleen & $1(0.28 \%)$ & 361 \\
Liver & $1(0.27 \%)$ & 366 \\
Lymph nodes & 11 & 17 \\
Testes & 11 & 20
\end{tabular}


charts for the purpose of correlation. There were no known cases of familial Mediterranean fever in this group or in their relatives.

\section{RESULTS}

Seventy-two of the 391 necropsied cases (18.4\%) had local amyloid deposits. There was no predilection for either of the sexes or for any ethnic groups. Table I shows the incidence of positive specimens for each organ. In 47, amyloid was found in one organ only (Table II), in 20 in two organs, in four in three organs, and in one in four organs (Table III).

\section{TABLE I I}

DIAGNOSIS AND AGE IN 47 CASES WITH AMYLOID IN ONE ORGAN

\begin{tabular}{|c|c|c|c|}
\hline Organ & Diagnosis & $\begin{array}{l}\text { No. of } \\
\text { Cases }\end{array}$ & Age (yr.) \\
\hline \multirow[t]{4}{*}{$\begin{array}{l}\text { Islets of } \\
\text { Langerhans }\end{array}$} & $\begin{array}{l}\text { Diabetes mellitus, arterio- } \\
\text { sclerotic cardiovascular disease }\end{array}$ & 10 & $63-78$ \\
\hline & Cirrhosis of liver & 2 & 28,63 \\
\hline & $\begin{array}{l}\text { Arteriosclerotic cardiovascular } \\
\text { disease, diabetes unknown }\end{array}$ & 3 & $58,65,70$ \\
\hline & Islet cell carcinoma & 1 & 76 \\
\hline \multirow[t]{2}{*}{ Adrenals } & Arteriosclerotic cardiovascular & & \\
\hline & $\begin{array}{l}\text { disease } \\
\text { Carcinoma (breast, stomach, 2) }\end{array}$ & $\begin{array}{l}6 \\
3\end{array}$ & $\begin{array}{l}67-85 \\
72-82\end{array}$ \\
\hline \multirow[t]{3}{*}{ Hypophysis } & Carcinoma (stomach, kidney) & 2 & 71,79 \\
\hline & $\begin{array}{l}\text { Arteriosclerotic cardiovascular } \\
\text { disease }\end{array}$ & 2 & 63,65 \\
\hline & Cirrhosis of liver & $\overline{1}$ & 39 \\
\hline \multirow[t]{3}{*}{ Brain } & Mental disease & 2 & 33,61 \\
\hline & Coma, unknown cause & $\overline{1}$ & 40 \\
\hline & $\begin{array}{l}\text { Arteriosclerotic cardiovascular } \\
\text { disease }\end{array}$ & 4 & $58-78$ \\
\hline Pancreas & $\begin{array}{l}\text { Arteriosclerotic cardiovascular } \\
\text { disease }\end{array}$ & 1 & 77 \\
\hline \multirow[t]{6}{*}{ Heart } & Arteriosclerotic cardiovascular & & \\
\hline & disease & 2 & 70,75 \\
\hline & Rheumatic heart disease & 1 & 37 \\
\hline & $\begin{array}{l}\text { Carcinoma (stomach), } \\
\text { arteriosclerotic cardiovascular }\end{array}$ & & \\
\hline & disease & 1 & 85 \\
\hline & Post-partum haemorrhage & 1 & 44 \\
\hline \multirow[t]{3}{*}{ Kidney } & Arteriosclerotic cardiovascular & & \\
\hline & disease & 1 & 75 \\
\hline & Reticulum cell sarcoma & 1 & 85 \\
\hline \multirow[t]{2}{*}{ Arteries } & Aneurysm of aorta & 1 & 67 \\
\hline & Endarteritis obliterans & 1 & 51 \\
\hline
\end{tabular}

Fifteen of 42 specimens of the anterior pituitary examined were positive for amyloid. The deposits were present in the connective tissue stroma between the cell groups. The quantity of amyloid was rarely sufficient to permit detection by ordinary light microscopy, although readily identifiable between crossed polars (Fig. 1). In five cases the adenohypophysis alone was involved and in 10 local deposits were present in other organs as well (Tables II and III). Diseases diagnosed in these cases are listed in these tables. The average age of this group was 66 years; only two patients (one aged 39 with cirrhosis

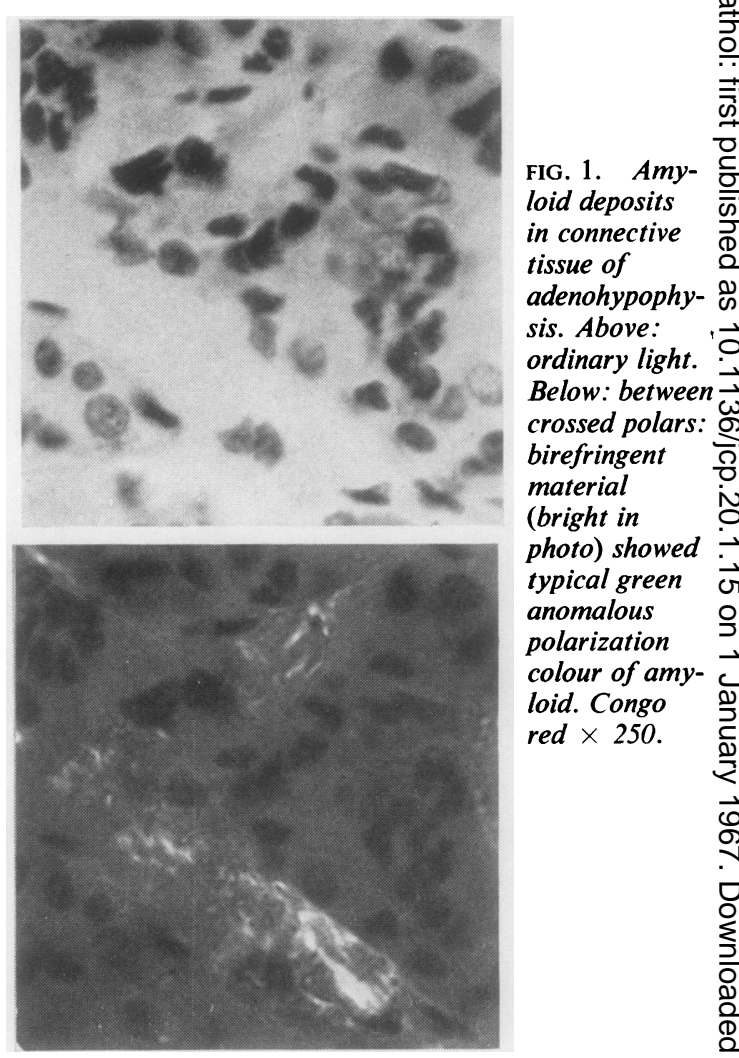

and one aged 45 with rheumatic heart disease) were $\overrightarrow{\underline{O}}$ below the age of 60 .

The islets of Langerhans were involved in 27 of 281 specimens of pancreas examined. The amyloid? deposits were located in the pericapillary connective tissue of the islet septa. They were variable in size? and extent, and frequently appeared as small focis involving a minimal area of the islet. When such minimal deposits were detected, they were linear $\frac{}{3}$ and apparently in contact with cells of the connective tissue (Fig. 2). Larger deposits compressed the islet 5 tissue and could be detected as Congo red staining ${ }^{D}$ deposits with ordinary light. The presence of amyloid was frequently accompanied by an obvious $N$ increase in collagen (Fig. 3). In 16 cases the islets alone were involved (Table II); in 11 local deposits were present in other organs, notably the hypophysis $\omega$ in five (Table III). Twenty-one of these 27 patients? were known to have had diabetes mellitus, two of them in association with hepatic cirrhosis; in three, diagnosed as arteriosclerotic cardiovascular disease,, it could not be determined whether or not diabetes $\frac{0}{-}$ was present; two others were cirrhotics known not to have suffered from diabetes, and one had an isletcell carcinoma. The average age of this group was $\varrho$ 67 years. 


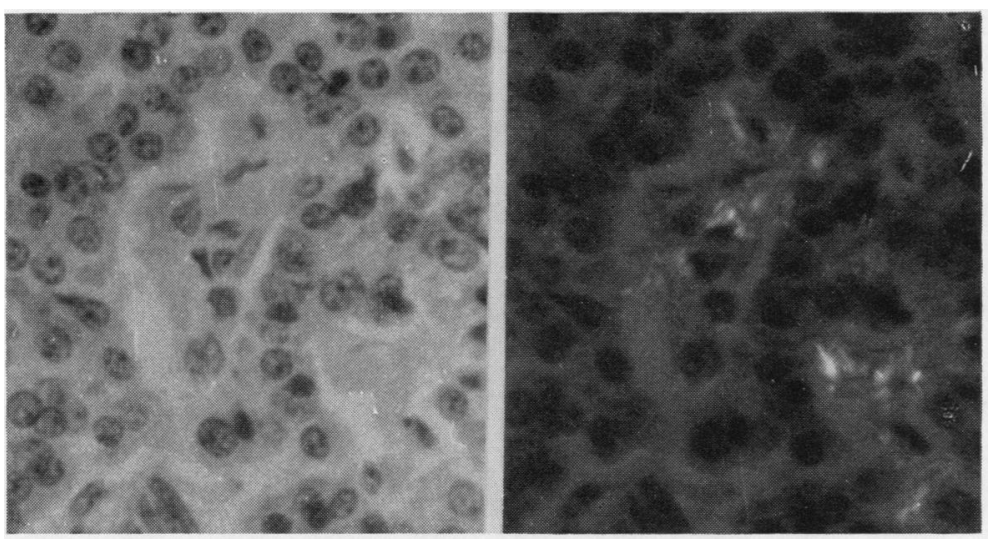

FIG. 2. Early amyloid deposits in connective tissue of islet of Langerhans. Left: ordinary light. Right: between crossed polars. Congo red $\times 250$.
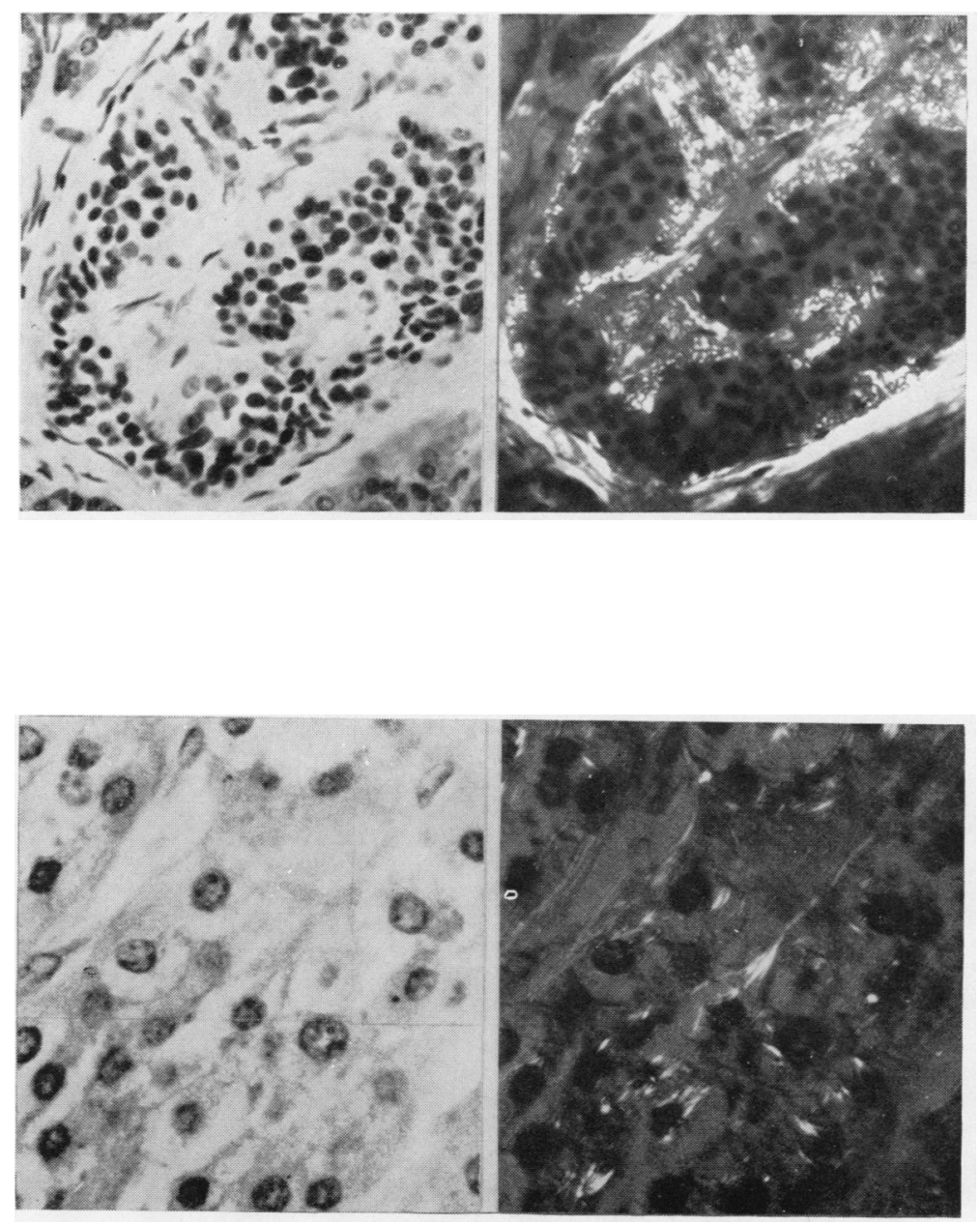

FIG. 3. Extensive amyloid deposits in islet of Langerhans with increase of collagen fibres. Left: ordinarylight. Kight: between crossed polars: some birefringent material was green (amyloid) and some white (collagen). Congo red $\times 100$.

FIG. 4. Minimal amyloid deposit along fibroblast in connective tissue of adrenal. Left: ordinary light. Right: between crossed polars. Congo red $\times 250$. 
TABLE III

DIAGNOSIS AND AGE IN 25 CASES OF AMYLOID IN TWO TO FOUR ORGANS

Age Diagnosis Organs with Amyloid

Islets Hypo- Adrenals Lung Brain Heart Pancreas Kidney Others

Amyloid in Two Organs

71 Diabetes, arteriosclerotic cardiovascular disease

60 Diabetes, arteriosclerotic cardiovascular disease

58 Diabetes, arteriosclerotic cardiovascular disease

Diabetes, cirrhosis

$\begin{array}{ll}55 & \text { Diabetes, cirrhosis } \\ 74 & \text { Diabetes, arteriosclerotic }\end{array}$

cardiovascular disease

64 Diabetes, arteriosclerotic

cardiovascular disease

76 Diabetes, arteriosclerotic

cardiovascular disease

74 Bronchiectasis, arteriosclerotic cardiovascular disease

60 Arteriosclerotic cardiovascular disease

60 Arteriosclerotic cardiovascular disease, cholelithiasis

78 Arteriosclerotic cardiovascular disease

80 Arteriosclerotic cardiovascular disease

66 Carcinoma of breast

85 Arteriosclerotic cardiovascular disease

physis

Arteriosclerotic cardiovascular disease

Multiple myeloma

Carcinoma of lung

Arteriosclerotic cardiovascular disease

74 Arteriosclerotic cardiovascular disease

45 Rheumatic heart disease Amyloid in Three Organs

74 Diabetes, arteriosclerotic cardiovascular disease

74 Diabetes, cirrhosis
89 Diabetes, arteriosclerotic cardiovascular disease

80 Arteriosclerotic cardiovascular disease

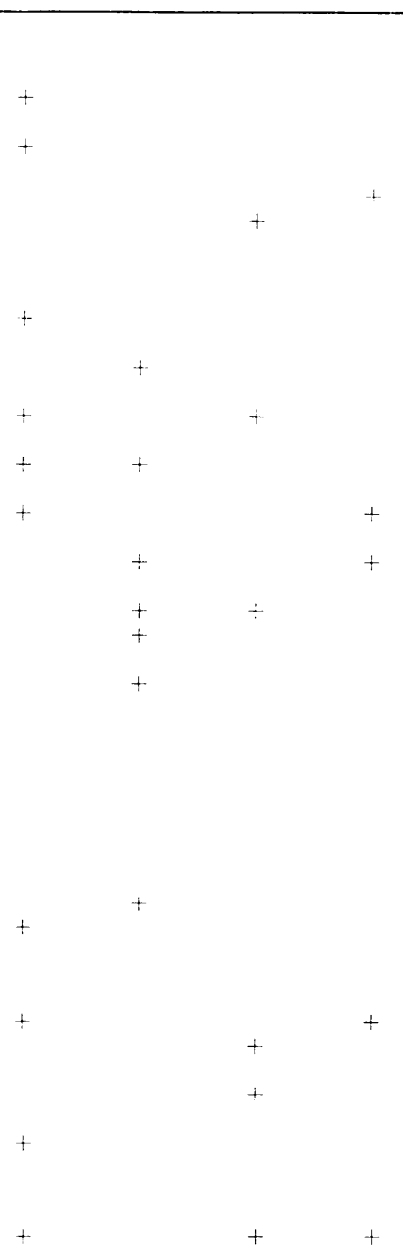

Amyloid in Four Organs

89 Diabetes, arteriosclerotic cardiovascular disease

In order to gain a clearer view on the relation of diabetes to local deposits of amyloid in the islets, an additional 123 consecutive necropsies were reviewed in which the pancreas was one of seven organs available, bringing the total number of cases in which pancreas was available to 402 . The presence or absence of amyloid in the islets was then correlated with information gleaned from the patients' charts relevant to diabetes. Thirty-eight of the $\mathbf{4 0 2}$ were diabetics. Of these all but four showed amyloid in the islet tissue. Among 308 documented non-diabetics only the three previously mentioned had demonstrable amyloid deposits (Table IV). In the remaining
TABLE IV

CORRELATION OF DIABETES AND AMYLOID IN ISLETS OF LANGERHANS

Total

Examined Islet Amyloidosta

Diabetic

Non-diabetic

Total

38
308

308

$34(90 \%)$

$3(1 \%)$

37

56 cases the patients' charts contained no information as to the absence or presence of diabetes; in thi group five positive specimens were found.

The 34 diabetic patients with amyloid included 
18 females and 16 males. Two died between the ages of 41 and 50 years, 18 between 51 and 70, and 14 above 70 . The known duration of the disease was less than 10 years in 12, 10-20 years in seven, longer than 20 in two, 'longstanding' in six, and unknown in five. In two, the diagnosis was established at the final admission. None of the patients had juvenile diabetes. Treatment also varied: nine had received diet only; four, oral hypoglycaemic drugs; 11, insulin. Two had received no therapy at all. In eight the mode of treatment could not be verified.

The adrenal was the site of amyloid deposits in 16 of 298 cases (Table I). Earliest amyloid deposits appeared in the connective tissue between the cell cords (Fig 4). The involvement was focal in character, the parenchymal cells in the region affected appearing smaller than those of adjacent normal tissue. The average age of these patients was 75 , only one being younger than 65 .

In 12 of 226 cases, amyloid was found in the central nervous system. Most commonly, these deposits were located in the meningeal or small intracerebral vessels and only occasionally in relation to the glia. In two of the cases the only deposits present were small, round amyloid bodies, within the substance of the brain. These specimens were random ones routinely obtained at necropsy; usually there was no note as to the site of the specimen, nor the reason for the choice of this particular site. As frequently occurs in retrospective studies, clinical details pertinent to this finding were usually lacking. Nine of the patients, whose mean age was 70 , had been diagnosed as cases of arteriosclerotic cardiovascular disease and three of them were diabetics. The three remaining cases were significantly younger, 33,40 , and 61 years, and had prominent cerebral disorder (Table II).

Small amyloid deposits were found in the hearts of nine patients. In all but one small vessels were involved, and in three minimal sarcolemmal deposits were present. Five were arteriosclerotics, ranging in age from 70 to 89 years, two with associated carcinomata (stomach and lung) and diabetes mellitus. The remaining four ranged in age from 37 to 55 (Tables II and III); in two with rheumatic heart disease, amyloid was located in the myocardium neighbouring the insertion of the diseased valve.

In six cases amyloid deposits were present in the alveolar septa of the lung (Table III). Except for one patient with cirrhosis who died at the age of 55 , their ages ranged from 74 to 89 years.

\section{DISCUSSION}

Amyloid can be diagnosed only on the basis of its staining properties. Although a variety of dyes are available, Congo red, the traditional amyloid stain, has been augmented in specificity and sensitivity by the application of polarization microscopy. The green anomalous polarization colour of Congo-redstained amyloid is an expression of the filamentous ultrastructure of amyloid demonstrable by electron microscopically. This feature makes possible the elimination of false-positive interpretations resulting from non-specific staining and false negatives due to hesitancy to identify small deposits as amyloid, both of which were not uncommon with ordinary light microscopy. Indeed, the specific green birefringence between crossed polars permits the detection of amyloid in quantities as yet invisible by ordinary light. The efficiency of the method has been proven in a large series of necropsies and biopsies followed through to necropsy (Heller et al., 1964; Heller, Gafni, and Sohar, 1966). At present, at least, the combination of polarization microscopy and Congo-red staining seems to be the most reliable and sensitive tool for the identification of amyloid.

The striking feature of this series is the surprisingly high frequency with which amyloid was found. This is a minimal incidence. Not more than two sections of each organ were examined, and not all organs were represented in the method of every necropsy. Notably the adenohypophysis, the most commonly affected organ in this survey, was absent among the available specimens in the overwhelming majority of cases.

The overall incidence of $18.4 \%$ assumes its full significance only with the realization of a steady rise with age, reaching a maximum of $36 \%$ in the 100 cases between the ages of 70 and 90 (Table V). The

\section{TABLE V}

INCIDENCE OF AMYLOID DEPOSITS ACCORDING TO AGE

\begin{tabular}{lcc}
\multicolumn{1}{c}{ Age } & $\begin{array}{l}\text { Total } \\
\text { Examined }\end{array}$ & Positive \\
\hline $0-10$ & 66 & $0(0 \%)$ \\
$10-30$ & 22 & $1(4 \cdot 5 \%)$ \\
$30-50$ & 47 & $6(12 \cdot 7 \%)$ \\
$50-70$ & 156 & $29(18 \cdot 6 \%)$ \\
$70-90$ & 100 & $36(36 \%)$ \\
Total & 391 & $72(18 \cdot 4 \%)$
\end{tabular}

frequent occurrence in old age of isolated amyloid deposits in the heart and brain has been previously well documented. This study demonstrates their even more common occurrence in the adenohypophysis, adrenals, and islets of Langerhans. As far as islet involvement is concerned, the clinical correlation with diabetes seems well established. Indeed, the presence of islet amyloid in $90 \%$ of the diabetics in this series indicates that this finding at necropsy is highly suggestive of diabetes. All of these cases were of diabetes with its onset in maturity. Another 
possible association deserving further study is the finding of amyloid deposits in five of 14 cirrhotics examined. In four (only two of them documented diabetics) the deposits occurred in the islets of Langerhans. The involvement of the adrenal and adenohypophysis, for the present at least, can be correlated only with old age.

In another group of cases, the amyloid was found in diseased areas: in cerebral tissue in two psychotics, in the neighbourhood of the diseased valves in two patients with rheumatic heart disease, in the affected vessels of thromboangiitis obliterans, and in the wall of an aortic aneurysm. These patients, for the most part, were the youngest of the series.

It would seem then, that microdeposits of amyloid frequently occur (1) in association with senescence, (2) in organs of internal secretion, (3) at the sites of pathological lesions.

We do not interpret the findings as indicating that these deposits, frequently detectable only by virtue of the polarizing microscope, are the cause of disease. Indeed, their small size and focal nature within the affected organs suggest that they are the products of a local pathological process.

The finding of focal deposits, as described above, in more than one organ does not justify the diagnosis of generalized amyloidosis. Non-systemic microdeposits of amyloid are readily distinguishable from systemic amyloidosis. There is no evidence of the widespread vascular involvement in virtually all organs which characterizes systemic amyloidosi They show a different organ predilection, sparing the kidney, liver, and spleen. Histologically amyloi first appears in relation to the pericapillary connects ive tissue.

This study was supported in part by research grang AM-09272 of the U.S. Public Health Service, Nationat Institutes of Health, Bethesda, Maryland, U.S.A.

Our thanks are due to Dr. Moshe Wolman, Head $\vec{\phi}$ the Department of Pathology at Tel-Hashomer Hospitat, for permission to examine his material and to Miv Shlomo Weinstock for technical assistance.

\section{REFERENCES}

Blum, A., and Sohar, E. (1962) Lancet, 1, 721.

Buerger, L., and Braunstein, H. (1960) Amer. J. Med., 28, 357.

Ehrlich, J. C., and Ratner, I. M. (1961). Amer. J. Path., 38, 49.

Gellerstedt, N. (1938). Beitr. path. Anat., 101, 1.

Heller, H., Gafni, J., and Sohar, E. (1966). In The Metabolic Basf: of Inherited Disease, edited by J. B. Stanbury, J. B. Wyngaarde and D. S. Fredrickson. 2nd ed., p. 995. McGraw-Hill, Ne疋 York.

—, Missmahl, H. P., Sohar, E., and Gafni, J. (1964). J. Paik. Bact., 88, 15.

Hüsselmann, H. (1955). Virchows Arch. path. Anat., 327, 607. Missmahl, H. P., and Hartwig, M. (1954). Dtsch. Z. Nervenheilk, $171,173$.

Pomerance, A. (1965). Brit. Heart J., 27, 697.

Porta, E. A., Yerry, R., and Scott, R. F. (1962). Amer. J. Path., 4 623.

Schwartz, P., Kurucz, J., and Kurucz, A. (1965). J. Amer. Geriā Soc., 13, 199.

$\longrightarrow,-$ (1965). J. Amer. Geriat. Soc., 13, 718.

Vassar, P. S., Culling, C. F. (1961). Amer. J. clin. Path., 36, 244. 